\title{
Pulmonary Mass Lesions: CT Scan Diagnostic-Impressions and FNAC Diagnoses - A Correlative Study
}

\author{
Biswas $\mathbf{P}^{1}$, Datta $A^{2}$, De $A^{3}$, Sinha $L K^{4}$ \\ ${ }^{1}$ Dr Pintu Biswas, Post Graduate Resident, Department of Radiodiagnosis, Agartala Goverment Medical College \& GB \\ Pant Hospital, Agartala, Tripura. PIN-799006, ${ }^{2}$ Dr Abhijit Datta, Associate Professor, Department of Pathology, \\ Agartala Goverment Medical College \& GB Pant Hospital, PO- Kunjaban, Agartala, Tripura, ${ }^{3}$ Dr Asim De, Associate \\ Professor, Department of Radiodiagnosis, Agartala Goverment Medical College \& GB Pant Hospital, Agartala, Tripura, \\ ${ }^{4}$ Dr Lakshmi Kanta Sinha, Associate Professor, Department of Radiodiagnosis, Agartala Goverment Medical College \& \\ GB Pant Hospital, Agartala, Tripura.
}

Address for correspondence: Dr. Abhijit Datta, Associate Professor, Department of Pathology, Agartala Goverment Medical College \& GB Pant Hospital, PO-Kunjaban, Agartala, Tripura, PIN- 799006. Email: abhijitpath62@gmail.com

\begin{abstract}
Introduction: Bronchogenic carcinoma, the commonest pulmonary mass lesion, is the leading cause of cancer related death globally. Computed tomography (CT) scan is often used for evaluation of pulmonary mass lesions to have an initial diagnostic impression for deciding on next course of actions in clinical management. So, it becomes highly imperative to study the correlation of CT scan-diagnoses with pathological diagnoses. Till date such correlative studies are very meagre from north-eastern part of India. This study was designed to address this deficiency. Aim: To correlate CT scandiagnoses of pulmonary mass lesions with the pathological diagnoses made on fine needle aspiration cytology (FNAC). Materials and Methods: Ninety subjects with pulmonary mass lesions were included. CT scan evaluation and CTguided FNAC were performed. Important clinical profiles, radiological diagnostic impressions on nature of the lesions (malignant/benign) and cytological diagnoses were recorded. Finally, a radio-cytological correlation of diagnoses was done. Results: Out of 90 cases, CT scans diagnosed 81 cases as malignant and nine as benign. On FNAC, there were 73 malignant and nine benign lesions and in eight cases aspirates were unsatisfactory. An overall radio-cytological correlation of $92.6 \%$ was observed. The sensitivity and specificity of CT scan for detecting malignancy in pulmonary mass lesions were found to be $94.5 \%$ and $55.5 \%$ respectively with an overall diagnostic accuracy of $89 \%$. Conclusion: CT scan study is a very useful non-invasive diagnostic modality in the clinical evaluation of lung masses. CT-guided FNAC is a simple, rapid and safe procedure with high yielding rate of pathological diagnoses.
\end{abstract}

Key words: CT scan, diagnostic accuracy, FNAC, pulmonary mass lesions, radio-cytological correlation.

\section{Introduction}

A pulmonary mass lesion is any pulmonary, pleural or mediastinal lesion detected on chest radiographs as an area of opacity more than $3 \mathrm{~cm}$ in diameter [1]. Computed tomography (CT) is the imaging modality most often used to evaluate pulmonary mass. The goal of radiologic evaluation of pulmonary mass lesions is to differentiate noninvasively between benign and malignant lesions as accurately as possible [2]. The main morphologic characteristics that help to differentiate benign from malignant lesions on CT

Manuscript received $10^{\text {th }}$ May 2016

Reviewed: $24^{\text {th }}$ May 2016

Author Corrected: $6^{\text {th }}$ June 2016

Accepted for Publication $18^{\text {th }}$ June 2016 include: Margins - malignant lesions have an irregular, ill defined, lobulated or spiculated margin while benign lesions tend to have a smooth, sharply defined edge; Shape- lung carcinomas tend to be irregular, lobulated or notched while hamartomas and metastases may be round or oval and Pattern of opacity - lesions with pure ground glass opacity (GGO) and mixed GGO are more likely to be malignant than a solid opacity [3].

Fine Needle Aspiration Cytology (FNAC) was first used by Martin and Ellis as a diagnostic tool [4]. Leyden in 1883 and Menbriel in 1986 introduced the technique as diagnostic lung puncture for detection of 
malignancy and infections. FNAC not only distinguishes between benign and malignant lesions but also helps in tumor typing of lung cancer, so initiation of specific therapy like radiotherapy, chemotherapy or surgery is possible without unnecessary delay [5].

The lung mass has a wide range of differential diagnoses like bronchogenic carcinoma, lung metastasis, mycobacterial or fungal pneumonia, lung abscess, pulmonary pseudotumor, round atelectasis; other less common entities include pulmonary arteriovenous malformation, hamartomas, bronchogenic cyst, pulmonary sequestration \& hydatid cyst etc.

Bronchogenic carcinoma is the commonest diagnosis of pulmonary mass. It is divided into two major histologic groups: non- small cell lung carcinoma (NSCLC) and small cell lung carcinoma.

NSCLC is further subdivided into the following histologic types: squamous cell carcinoma, adenocarcinoma and large cell carcinoma [6].

Making an initial diagnostic impression on CT scan often becomes important as far as next course of actions in the clinical management and apprehensions of patient and treating doctor are concerned. A need was therefore felt to assess the correlation of radiological diagnoses of pulmonary mass lesions made on CT-evaluation with the FNAC diagnoses, in this state of Tripura, as to our knowledge no such study has been conducted here till date.

\section{Materials and Methods}

This prospective observational study was carried out in the Department of Radio-Diagnosis in association with Department of Pathology at Agartala Government Medical College \& G.B.Pant Hospital, Agartala, Tripura, with a study period of one and half years during 2014- 15.

Aim of the study was to correlate radiological diagnoses of pulmonary mass lesions made on CT scan study with the diagnoses on FNAC.

All cases referred for CT scan study of chest, in whom pulmonary mass lesions were detected on CT scan, where fine needle aspiration (FNA) could be performed were included in this study. Cases of pulmonary mass lesions where FNA was not possible owing to unfavourable location, persons with known bleeding diathesis, known cases of advanced chronic obstructive pulmonary disease, known cases of pulmonary arterial hypertension, known cases of contralateral pneumonecctomy, pregnant women and cases who did not give informed consent to participate in the study were excluded. A total of 90 patients were studied mostly referred from the departments of Medicine and Respiratory Medicine.

Multidetector Computed Tomography (MDCT) machine (PHILIPS, model BRILLIANCE 16) was used. Fine needle aspiration (FNA) was performed under CTguidance. Non-contrast and contrast CT scan images were obtained following intravenous administration of $50 \mathrm{ml}$ of non-ionic contrast media (Iohexol, GE health care) at the rate of $3 \mathrm{ml} / \mathrm{sec}$ using pressure injector.

Central or peripheral lung mass detected on CT sections were characterised based on the site, size, margins, enhancement pattern, presence of calcification, cavitation, hilar and mediastinal lymph nodes, pleural and chest wall involvement etc. Search was made for any additional lesions in ipsilateral and contralateral lungs.

Lymph nodes were assessed for size, shape, number and were classified according to lymph node stations. Visualised parts of liver and adrenals were assessed for any evidence of metastasis.

FNA was performed with $23 \mathrm{G}$ disposable needle fitted in $20 \mathrm{ml}$ disposable syringe using a metallic plunger (Amar Udyog, Chandigarh). After FNA procedure, the patients were kept under observation for 30 minutes for any complication like pneumothorax.

The smears were stained with Giemsa and Hematoxylin \& Eosin (H \& E) stains. Microscopy of smears was performed using binocular microscope (Olympus, 21X).

Radiological diagnoses on CT scan and cytological diagnoses on FNAC were recorded and finally the radiological diagnoses were correlated with those of FNAC diagnoses.

Statistical analysis: Data has been expressed in number and in frequency in terms of percentage wherever felt necessary. Statistical Package for the Social Sciences (SPSS) software programme (version 21) was used for data analysis. Statistical inferences have been given using 95\% confidence interval and Fisher's exact test. 


\section{Results}

Demographic and clinical profiles of the study subjects are given in Table-1.

Table-1: Demographic and clinical profiles of the subjects $(n=90)$.

\begin{tabular}{|c|c|c|}
\hline Sex : & No of patients & Percentage \\
\hline Male & 74 & 82.2 \\
\hline Female & 16 & 17.8 \\
\hline \multicolumn{3}{|l|}{ Smoking habit: } \\
\hline Smoker & 73 & 81.1 \\
\hline Non-smoker & 17 & 18.9 \\
\hline \multicolumn{3}{|l|}{ Symptoms: } \\
\hline Loss of appetite & 83 & 92.3 \\
\hline Weight loss & 72 & 80 \\
\hline Cough & 71 & 78.8 \\
\hline Shortness of breathing & 69 & 76.7 \\
\hline Horner's syndrome & 12 & 13.3 \\
\hline \multicolumn{3}{|l|}{ Physical findings: } \\
\hline Pallor & 71 & 78.8 \\
\hline Clubbing & 45 & 50 \\
\hline Lymphadenopathy & 14 & 15.6 \\
\hline Engorged neck vein & 6 & 6.7 \\
\hline $\mathrm{HPOA}^{*}$ & 1 & 1.1 \\
\hline
\end{tabular}

* HPOA - Hypertrophic pulmonary osteoarthropathy

Most of the subjects were in 6th and 7th decade of their life - 60 out of total 90 (66.7\%). They showed mass lesions of variable sizes and shapes. Maximum number of mass lesions were detected in the upper zone of right lung - seen in 33 cases $(36.7 \%)$ followed by $21(23.3 \%)$ in upper zone of left lung.

Maximum number of masses were seen located peripherally- 46 in number $(51.1 \%)$. Central masses were seen in 44 $(48.9 \%)$ cases. Most of the lesions were of more than $7 \mathrm{~cm}$ in size with mean size of $7.47 \mathrm{~cm}$.

FNAC diagnoses were possible in 82 cases and in eight cases ( $8.9 \%$ of total 90 cases taken up for the study) the aspirated materials were unsatisfactory for interpretation owing to bloody or scanty nature of the aspirates.

Those eight cases were excluded during relevant statistical analysis. In 71 cases $(86.6 \%$ of all cytologically diagnosed cases) primary malignant lesions were found on FNAC.

Break up of different cytological diagnoses made on FNAC and radiologically diagnosed nature of lesions (malignant/benign) on CT scan alongwith correlation of the nature of each cytological diagnosis with that of the radiological diagnosis are given in Table-2.

Pattern of contrast enhancement alongwith CT and FNAC diagnoses are given in Table-3. Correlation of spiculated margin and nature of lesions on FNAC are given in Table-4. 
Table-2: Break up of cytological diagnoses on FNAC and correlation of radiologically diagnosed nature of lesions with those cytological diagnoses.

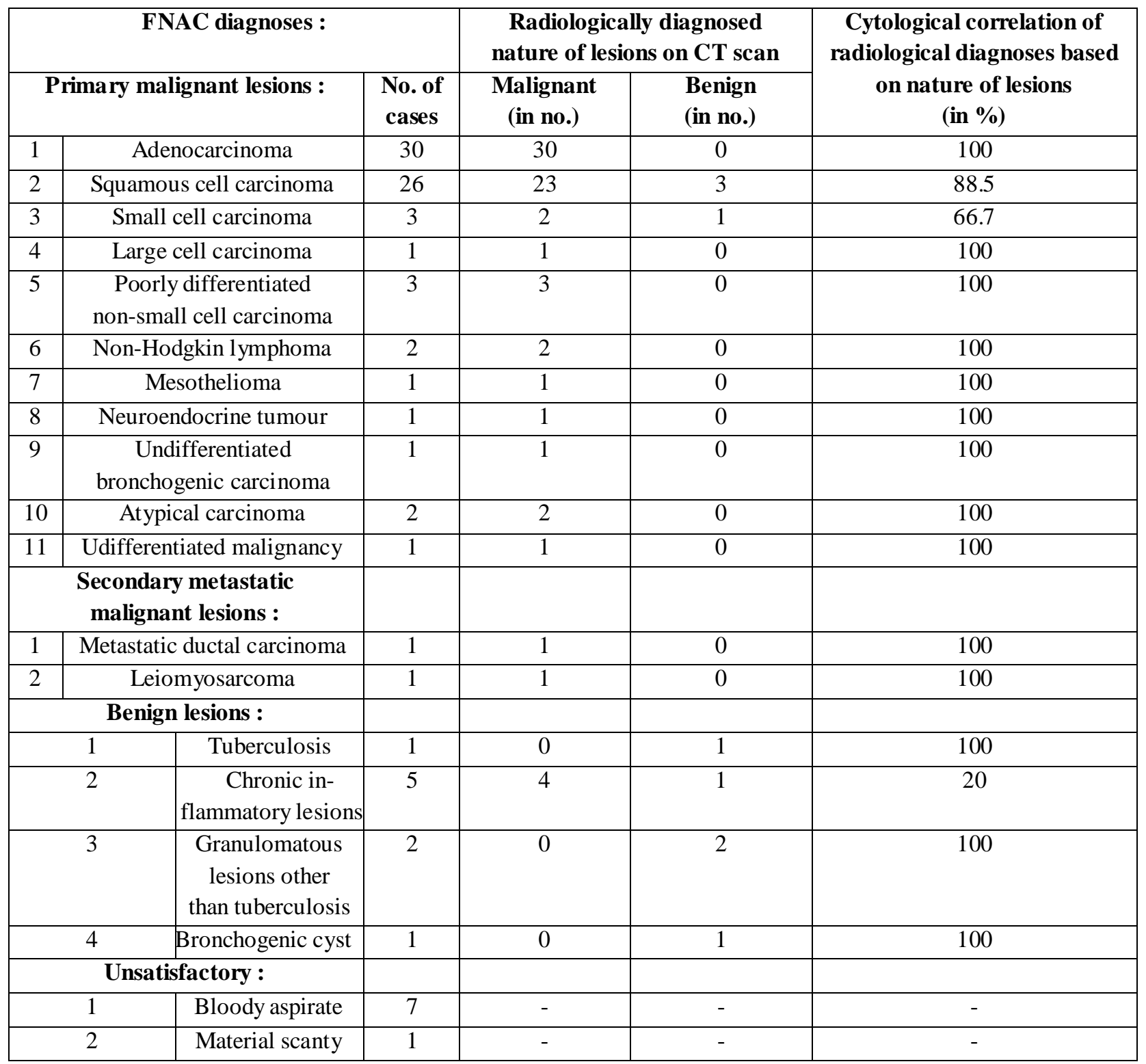

Table-3: Enhancement pattern of lesions and relation with radiologically and cytologically diagnosed nature of those lesions.

\begin{tabular}{|c|c|c|c|c|c|c|}
\hline \multicolumn{3}{|c|}{ Radiologically diagnosed nature of lesions } & \multicolumn{3}{|c|}{ Nature of lesions on FNAC } & \multirow[t]{2}{*}{ Total } \\
\hline & & & Malignant & Benign & Unsatisfactory & \\
\hline \multirow{4}{*}{ Benign } & \multirow{3}{*}{$\begin{array}{c}\text { Enhancement pattern } \\
\text { of the mass }\end{array}$} & Heterogenous & 0 & 2 & 0 & 2 \\
\hline & & Homogenous & 4 & 2 & 0 & 6 \\
\hline & & No enhancement & 0 & 1 & 0 & 1 \\
\hline & \multicolumn{2}{|c|}{ Sub Total } & 4 & 5 & $\mathbf{0}$ & 9 \\
\hline \multirow{4}{*}{ Malignant } & \multirow{3}{*}{$\begin{array}{c}\text { Enhancement pattern } \\
\text { of the mass }\end{array}$} & Heterogenous & 68 & 4 & 8 & 80 \\
\hline & & Homogenous & 1 & 0 & 0 & 1 \\
\hline & & No enhancement & 0 & 0 & 0 & 0 \\
\hline & \multicolumn{2}{|c|}{ Sub Total } & 69 & 4 & 8 & 81 \\
\hline & \multicolumn{2}{|c|}{ Grand Total } & 73 & 9 & 8 & 90 \\
\hline
\end{tabular}


Table-4: Correlation of spiculated margin of the mass as found on CT scan with nature of lesions on FNAC.

\begin{tabular}{|c|c|c|c|c|c|c|}
\hline \multirow{2}{*}{\multicolumn{3}{|c|}{$\begin{array}{l}\text { Radiologically diagnosed nature } \\
\text { (Benign / malignant) }\end{array}$}} & \multirow{3}{*}{$\begin{array}{c}\text { Total } \\
5\end{array}$} & \multicolumn{3}{|c|}{ Nature on FNAC } \\
\hline & & & & \multirow{2}{*}{$\frac{\text { Benign }}{3}$} & \multirow{2}{*}{$\frac{\text { Malignant }}{2}$} & \multirow{2}{*}{$\frac{\text { unsatisfactory }}{0}$} \\
\hline \multirow{3}{*}{ Benign } & \multirow{2}{*}{$\begin{array}{l}\text { Spiculated } \\
\text { margin }\end{array}$} & Present & & & & \\
\hline & & Absent & 4 & 2 & 2 & 0 \\
\hline & \multicolumn{2}{|c|}{ Sub-Total } & 9 & 5 & 4 & $\mathbf{0}$ \\
\hline \multirow{3}{*}{ Malignant } & \multirow{2}{*}{$\begin{array}{l}\text { Spiculated } \\
\text { margin }\end{array}$} & Present & 66 & 3 & 55 & 8 \\
\hline & & Absent & 15 & 1 & 14 & 0 \\
\hline & \multicolumn{2}{|c|}{ Sub-Total } & 81 & 4 & 69 & 8 \\
\hline \multicolumn{3}{|c|}{ Grand Total } & 90 & 9 & 73 & 8 \\
\hline
\end{tabular}

Important associated findings on CT scan with corresponding radiological and cytological nature of the mass lesions are shown in Table-5. Overall correlation of CT scan diagnoses with FNAC diagnoses for malignant \& benign lesions are shown in Table-6. Taken into consideration of each type of malignant and benign lesions in totality an average radiocytological correlation of $92.6 \%$ was observed.

Table-5: Associated CT scan findings with corresponding radiological and cytological nature of the mass lesions.

\begin{tabular}{|c|c|c|c|c|c|c|c|}
\hline \multirow[t]{2}{*}{ Findings } & \multicolumn{2}{|c|}{ Radiological nature } & \multicolumn{3}{|c|}{ Cytological Nature } & \multicolumn{2}{|c|}{ Total } \\
\hline & Benign & $\begin{array}{c}\text { Maligna } \\
\text { nt }\end{array}$ & Benign & $\begin{array}{c}\text { Maligna } \\
\text { nt }\end{array}$ & $\begin{array}{c}\text { Unsatisfacto } \\
\text { ry }\end{array}$ & No. & $\begin{array}{l}\text { Frequency } \\
\text { (in \% of } \\
\text { total mass } \\
\text { lesions) }\end{array}$ \\
\hline Hilar enlargement & 5 & 62 & 6 & 54 & 7 & 67 & 74.4 \\
\hline $\begin{array}{l}\text { Widening of } \\
\text { mediastinum }\end{array}$ & 3 & 23 & 2 & 22 & 2 & 26 & 28.8 \\
\hline Calcification & 3 & 13 & 3 & 12 & 1 & 16 & 17.7 \\
\hline Lung collapse & 1 & 25 & 2 & 22 & 2 & 26 & 28.8 \\
\hline Chest wall invasion & 0 & 13 & 0 & 12 & 1 & 13 & 14.4 \\
\hline Mediastinal invasion & 0 & 8 & 0 & 7 & 1 & 8 & 8.8 \\
\hline $\begin{array}{c}\text { Contralateral tumor } \\
\text { nodule }\end{array}$ & 0 & 8 & 1 & 7 & 0 & 8 & 8.8 \\
\hline $\begin{array}{l}\text { Lymphangitic } \\
\text { carcinomatosis }\end{array}$ & 0 & 1 & 0 & 1 & 0 & 1 & 1.1 \\
\hline Pleural effusion & 3 & 45 & 2 & 46 & 0 & 48 & 53.3 \\
\hline Pericardial effusion & 0 & 4 & 1 & 2 & 1 & 4 & 4.4 \\
\hline SVC obstruction & 0 & 4 & 0 & 4 & 0 & 4 & 4.4 \\
\hline $\begin{array}{c}\text { Thick walled } \\
\text { Cavitary lesion }\end{array}$ & 0 & 13 & 1 & 10 & 2 & 13 & 14.4 \\
\hline $\begin{array}{l}\text { Endobronchial } \\
\text { location of mass }\end{array}$ & 0 & 17 & 1 & 13 & 3 & 17 & 18.8 \\
\hline \multicolumn{8}{|l|}{ Lymphadenopathy } \\
\hline Supra clavicular & 0 & 2 & 0 & 2 & 0 & 2 & 2.2 \\
\hline Scalene & 0 & 2 & 0 & 2 & 0 & 2 & 2.2 \\
\hline Mediastinal & 7 & 51 & 7 & 47 & 4 & 58 & 64.4 \\
\hline Subcarinal & 1 & 22 & 1 & 20 & 2 & 23 & 25.5 \\
\hline Hilar & 1 & 21 & 1 & 19 & 2 & 22 & 24.4 \\
\hline Peribronchial & 1 & 11 & 1 & 10 & 1 & 12 & 13.3 \\
\hline
\end{tabular}


Table-6: Correlation of CT scan diagnoses with FNAC diagnoses for malignant \& benign lesions.

\begin{tabular}{|c|c|c|c|c|}
\hline \multirow{2}{*}{$\begin{array}{c}\text { Nature of mass lesions on } \\
\text { CT scan study }\end{array}$} & \multicolumn{2}{|c|}{ FNAC diagnoses } & \multirow{2}{*}{$\begin{array}{c}\text { Correlation } \\
\text { (in \%) }\end{array}$} \\
\cline { 2 - 5 } & Malignant & Benign & 94.5 \\
\hline Malignant & 73 & 69 & 4 & 5 \\
\hline
\end{tabular}

Most of the adenocarcinomas were located peripherally (22 out of 30) and were present among the smokers (26 out of 30). Squamous cell carcinomas were more common in central location (16 out of 26) and among all the cases of squamous cell carcinomas six were associated with cavitation.

Among the three (3) small cell carcinoma seen in the present study, all were central and associated with hilar, subcarinal and mediastinal lymphadenopathy. All had associated mediastinal widening and hilar enlargement. The large cell carcinoma was located peripherally and measured $10.99 \mathrm{~cm}$ in size.

The sensitivity and specificity of CT scan study for detection of malignancy in pulmonary mass lesions were found to be $94.5 \%$ and $55.5 \%$ respectively and the overall diagnostic accuracy of CT scan study of pulmonary mass lesions was found to be $89 \%$.

No evidence of any post FNAC complication like pneumothorax was seen in any of the subjects in this study.

\section{Discussion}

In this study we found that lung mass was significantly more common in males than in females as found there were $82.2 \%$ males and $17.8 \%$ females. Gupta et al found the almost similar sex proportion in their study, where there were $86 \%$ males and $14 \%$ females [7]. Most of the patients of this present study were from 50 to 70 years comprising of $60 \%$ of total study population. The youngest patients was 40 years old ( 2 cases) and the oldest was aged 100 years. The age of the cases with pulmonary mass lesions seen in various other studies ranged from 40 to above 80 years [8- 12]. Smoking is found to be associated with $81.1 \%$ of patients with lung masses in this study. This finding is similar to observation by Rawat et al, where smoking was found to be the main risk factor for lung masses in $81.77 \%$ patients [9].

Most common symptoms associated with lung mass of present series was loss of appetite observed in 83 cases (92.2\%), followed by weight loss in 72 cases $(80 \%)$. These findings are consistent with those of Gopichand \& Praveena [11].

Bronchogenic Carcinoma is well known to have a multifaceted presentation. In the present study, most of the mass lesions were detected in upper zones of right lung $(36.7 \%)$ followed by upper zones of left lung $(23.3 \%)$. Both lungs were involved in four cases $(4.4 \%)$. These findings are comparable to the study by Hoque et al, where maximum number of masses were detected in right upper zone (25.5\%), followed by $19.6 \%$ in left upper zone [10]. In the study by Rawat et al both lungs were found to be involved in $2.96 \%$ of cases [9].

Majority of masses were seen to be located peripherally as seen in $51.1 \%$ of cases, while in $48.9 \%$ cases masses were central. Findings are quite consistent with study by Rawat et al, where central masses were $48.77 \%$ and peripheral mass is $51.23 \%$ [9]. Carcinomas typically have ill-defined margins which are irregular, spiculated or lobulated and may exhibit umbilication or a notch [13]. Margins of the malignant lesions in this series were mostly spiculated as seen in 57 cases (78.1\% of malignancies), followed by lobulated and occasionally smooth margins in rest of the malignant lesions. Almost similar observation (in $80 \%$ ) was made in in their study by Ningappa et al [14].

It is worth mentioning that in cavitating lung masses, wall thickness of less than $10 \mathrm{~mm}$ indicates a benign lesion in $95 \%$ of patients, and a wall thickness of more than $15 \mathrm{~mm}$ indicates a malignant lesion in more than $80 \%$ of patients [15].

A total of 10 (13.7\% of malignant lesions) thick walled cavitating malignant masses (figure-1) were seen in this study, among them 07 were centrally located and 06 were located peripherally. Cavitating lung masses were seen in $5.9 \%$ and $10 \%$ of cases in their study by Haque et al and Gopichand \& Praveena respectively [10, 11]. 


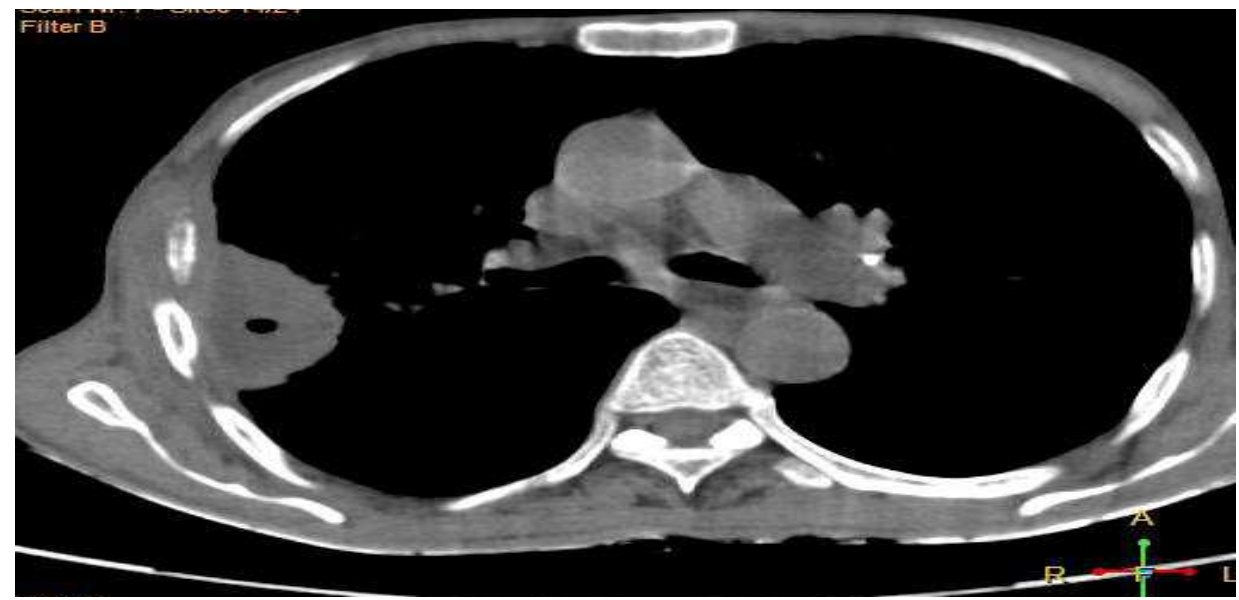

Figure 1: Axial image of CECT scan of chest showing cavitary lung mass (right) with rib destruction.(right) and contralateral hilar lymphadenopathy

An attenuation value above $185 \mathrm{HU}$ is strongly predictive of calcification [16]. Calcification was seen 16 cases (17.8\% of total mass lesions) which is comparable to the study by Shetty et al where calcification were seen in 16\% of cases [17]. In this study, there was 01 case $(1.1 \%)$ of nodular thickening of interlobular septa suggestive of lymphangitic carcinomatosis (figure-2) present in a peripherally located adenocarcinoma. Similar finding was seen by Shetty et al [17].

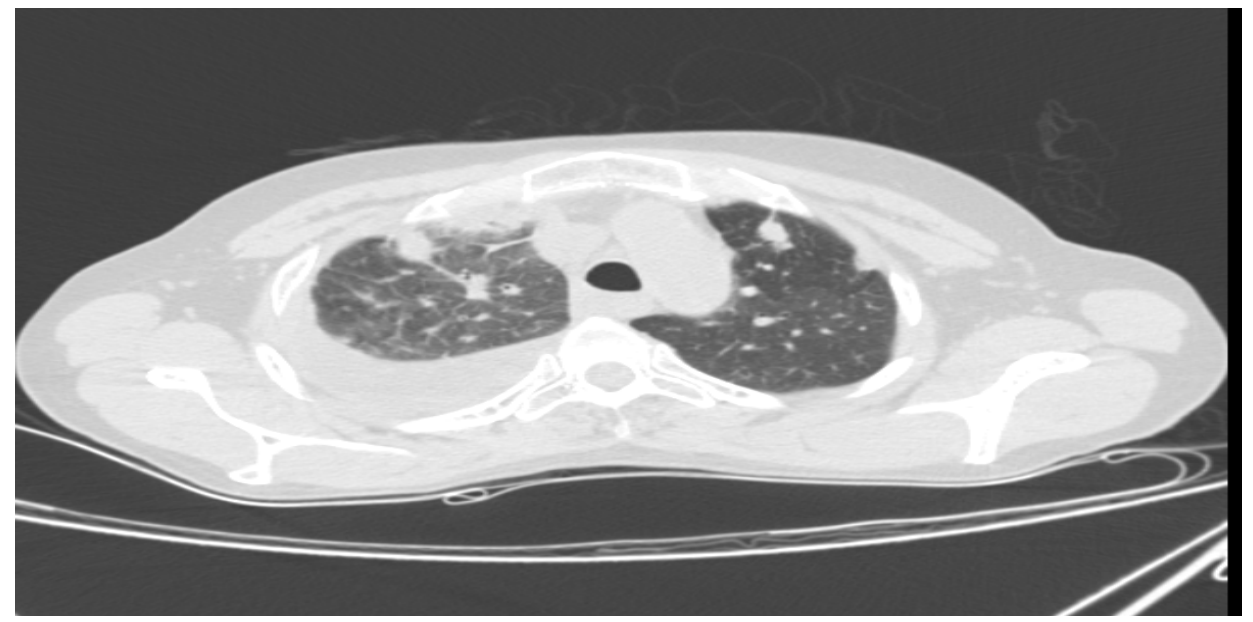

Figure 2: Axial image of CECT scan of chest (lung mode) showing nodular thickening of interlobular septa (suggestive of lymphangitis carcinomatosis). Multiple pulmonary nodules and right sided pleural effusion are also noted.

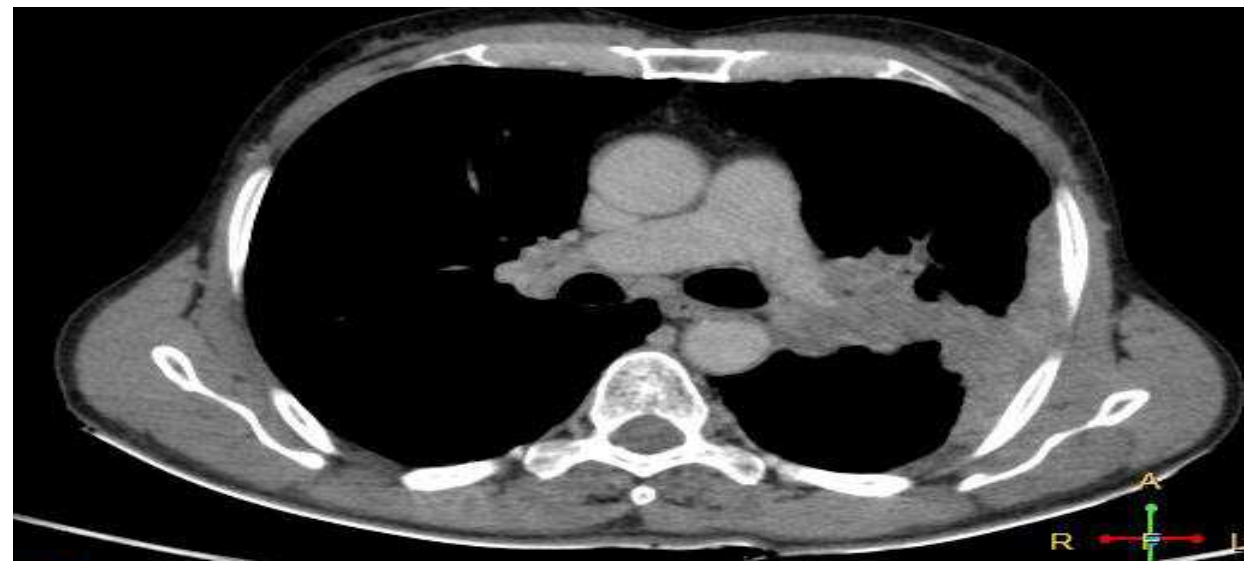

Figure 3: Axial image of CECT scan of chest shows left hilar mass lesion with left pulmonary artery invasion with mediastinal lymphadenopathy and also minimal pleural effusion. 
Extensive replacement of mediastinal fat by soft-tissue mass, or mass surrounding mediastinal vessels, trachea and esophagus or mass resulting in obvious invasion of one of these structures is mediastinal invasion. Mediastinal invasion (figure- 3) in present study was found in seven cases (9.6\% of malignancies), which is comparable to study by Gopichand \& Praveena where they found it in $10 \%$ cases [11]. Total 48 cases $(53.3 \%)$ of pleural effusion were seen in CT scan examination. Pleural effusion was seen in $60 \%$ and $34.5 \%$ of patients with lung masses in the studies by Pandhi et al and Shetty et al respectively [8,17]. Pericardial effusion was seen in two cancer cases $(2.7 \%$ of malignant lesions $)$ and both the cases were associated with adenocarcinoma. Pandhi et al noted its frequency to be $10 \%$ in their study [8]. In that study also the pericardial effusion were most commonly associated with adenocarcinoma.

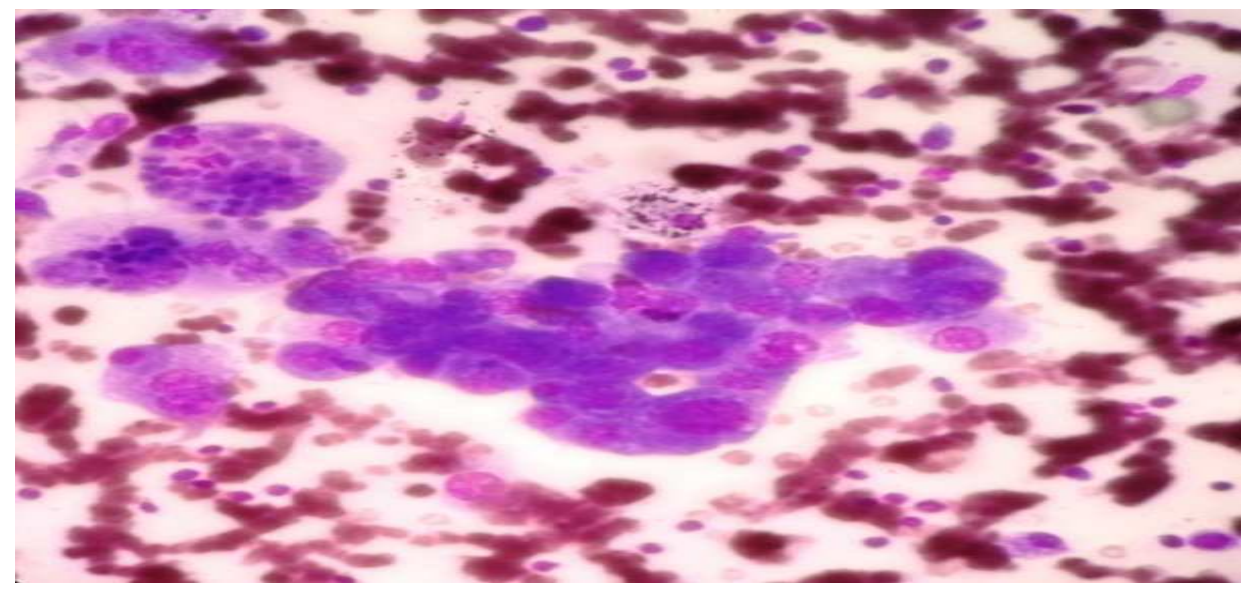

Figure-4: Photomicrograph of FNAC smear from a case of adenocarcinoma showing malignant glandular epithelial cells. (Giemsa X 400).

Mediastinal lymphadenopathy was detected in CT scan in 47 cases of malignancies $(64.4 \%)$, which is comparable to the study by Ningappa et al where mediastinal lymphadenopathy were seen in $48 \%$ cases [14].

In the study by Madan \& Bannur adenocarcinoma was the commonest cell type seen in $30 \%$ cases, followed by squamous cell carcinoma in $22.5 \%$ cases, which are near similar to the present study, where adenocarcinoma (figure- 4 ) was observed to be the most common epithelial cell type of malignancy (32.2\%), followed by squamous cell carcinoma (28.9\%) [18]. Small cell carcinoma (figure- 5) were noted in 3.3\% cases in this study which is consistent to JayaShankar et al, who noted it to be $3 \%$ [19]. Similar results were also seen in in a study by Singh et al, where it was found to be $4 \%$ [20]. In this study, large cell carcinoma was $1.1 \%$ of total lung mass lesions and frequency of this ranged from $2 \%$ to $2.7 \%$ in a couple of other studies [5,12]. Comparison of frequencies of different types of lung carcinomas among all pulmonary mass lesions as found in different studies is shown in Table-7.

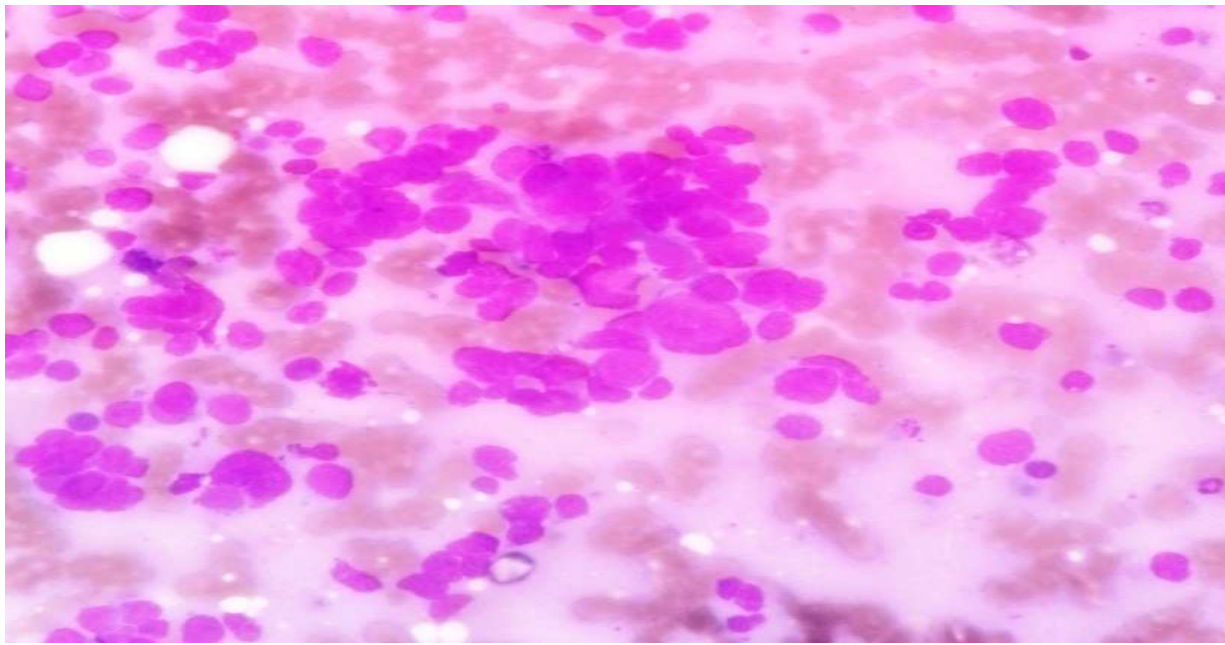

Figure-5: Photomicrograph of FNAC smear from a case of small cell carcinoma showing round neoplastic cells with very scant to absent cytoplasm and nuclear moulding. (Giemsa X 400) 
Table-7: Comparison of frequencies of different types of carcinomas out of all pulmonary mass lesions as found in different studies (figures in percentage) [7, 11, 18, 19, 21].

\begin{tabular}{|c|c|c|c|c|c|c|}
\hline Cell type & $\begin{array}{c}\text { Present } \\
\text { study }\end{array}$ & $\begin{array}{c}\text { Gupta et } \\
\text { al }\end{array}$ & Datta & $\begin{array}{c}\text { Madan and } \\
\text { Bannur }\end{array}$ & $\begin{array}{c}\text { Gopichand \& } \\
\text { Praveena }\end{array}$ & $\begin{array}{c}\text { JayaShankar et } \\
\text { al }\end{array}$ \\
\hline $\begin{array}{c}\text { Squmous cell } \\
\text { carcinoma }\end{array}$ & 28.9 & 42 & 47.3 & 22.5 & 30 & 51 \\
\hline Adenocarcinoma & 32.2 & 20 & 14.4 & 30 & 50 & 43 \\
\hline Small cell carcinoma & 3.3 & 14 & 6 & 0 & 5 & 3 \\
\hline Large cell carcinoma & 1.1 & 18 & 0 & 0 & 0 & 0 \\
\hline
\end{tabular}

Tuberculosis was detected in one case (1.2\% of total FNAC diagnoses) in the present study. Frequency of tuberculosis ranges from $2 \%$ to $12 \%$ as reflected in various studies $[10,19,21]$. This very low frequency of tuberculosis in our series of patients is probably because of very careful clinico-radiological evaluation of the lesions, so that most of the cases of this disease were efficiently diagnosed on available laboratory investigation procedures and on other supportive evidences.

In this study two (2.4\% of diagnosed mass lesions) metastatic lesions (metastatic ductal carcinoma and leiomyosarcoma, one case each.) were seen. This finding is comparable to the study by Konjengbam et al, where only one case $(2.5 \%)$ of metastatic lesion (metastatic breast carcinoma) was detected [22].

Material was unsatisfactory in 8 cases ( $8.9 \%$ of total mass lesions). Unsatisfactory materials in a small proportion of cases cannot be avoided and in various studies the proportions of unsatisfactory materials were found to be ranging from $5 \%$ to $12.3 \%[12,18,21-23]$.

No evidence of post FNAC complication was seen in any of the subjects in this study, which was probably because of very careful and efficient $\mathrm{CT}$ guided FNA procedures.

Correlations of CT scan diagnoses with that of FNAC for malignant \& benign lesions separately were found to be $94.5 \%$ and $55.5 \%$ respectively in our study. To our knowledge, no such separate radio-cytological correlation for malignant and benign mass lesion was worked out in any other study till date. However, in a study by Piplani et al, an overall cytoradiological correlation of $89.2 \%$ was found which is quite closer to our overall average correlation of 92.6\% [24]. The present study revealed that the sensitivity and specificity of CT scan study for detection of malignancy in pulmonary mass lesions was $94.5 \%$ and $55.5 \%$ respectively. In the study by Mondol et al, the sensitivity was $97 \%$ and specificity was $90 \%$, whereas JayaShankar et al found the sensitivity and specificity to be $84 \%$ and $76 \%$ respectively [5, 19]. The lower specificity of CT scan assessment found in our study might have been due to small sample size where a small number of benign lesions have been present. The overall diagnostic accuracy of CT scan study of pulmonary mass lesions in present study was $89 \%$ which is very closer to that of different other studies where a diagnostic accuracy of little more than $90 \%$ was found $[5,18,19,24]$.

\section{Conclusion}

Radiological diagnoses made on CT scan findings in the present study correlated well with the cytopathological diagnoses on FNAC and for malignant lesions the correlation is better than for the benign lesions. So, it can be concluded that CT scan study is a very useful non-invasive diagnostic modality in the clinical evaluation of lung masses. Further, CT-guided FNAC is a simple, rapid and safe procedure with high yielding rate of pathological diagnoses.
Funding: Nil, Conflict of interest: None initiated. Permission from IRB: Yes

\section{References}

1. Hansel DM, Balkier AA, MacMahon H, McLeod TC, Muller NL, Remy J. Fleischer Society: Glossary of Terms for Thoracic Imaging. Radiology 2008 Mar; 246 (3):697-722. 
2. Erasmus TT, Connolly ET, McAdams HP, Page H, Roggli LV. Solitary pulmonary nodule : part 1. Morphologic evaluation for differentiation of benign \& malignant lesion. Radiographics. 2000 Jan- Feb; 20(1): 43-55.

3. Li F, Sone $\mathrm{S}$, Abe H, Macmahon H, Doi K. Malignant versus benign nodules at CT screening for lung cancer : comparison of thin section CT findings. Radiology 2004 Dec; 233(3) : 793-8.

4. Mrtin HE, Ellis EB. Biopsy by needle puncture and aspiration. Ann Surg.1930 Aug; 92(2):169-81.

5. Mondol KS, Nag D, Das R, Mondol KP, Biswas P, Osta M. Computed tomogram guided fine-needle aspiration cytology of lung mass with histological correlation: A study in eastern India. South asian journal of cancer. $2013 \mathrm{Jan}$; 2(1):14-18.

6. W Richard Webb, Charles B, Higgins. Thoracic imaging. Second edition. Lippincott : Williams \& Wilkins 2011: 69-116, 271-3.

7. Gupta RC, Purohit SD, Sharma MP, Bhardwaj S. Primary bronchogenic carcinoma: Clinical profile of 279 cases from Midwest Rajasthan. Indian J chest dis allied Sci. 1998 Apr-Jun; 40 (2):109-16.

8. Pandhi N, Malhotra B, Kajal N, Prabhudesai RR, LC Nagaraja, Mahajan N. Clinicopathological profile of patients with lung cancer visiting chest and TB hospital Amritsar. Sch. J. App. Med. Sci. 2015; 3(2D):802-809.

9. Rawat J, Sindhwani G, Gaur D, Dua R, Saini S. Clinico-pathological profile of lung cancer in Uttarakhand. Lung India. 2009; 26(3): 74-6.

10. Hoque MS, Hashem MA, Hasan S, Siddique AB, Hossain A, Mahbub M et al. Role of CT scan in the evaluation of lung tumor with cytopathological correlation. Faridpur Med. Coll. J. 2014; 9(1):37-41.

11. Gopichand N, Praveena S. A study of computed tomography of the chest in bronchogenic carcinoma. Indian journal of applied research. 2015Apr;5(4):223-6.

12. Sengupta M, Saha K. Computed tomography guided fine needle aspiration cytology of pulmonary mass lesions in a tertiary care hospital : A two-year prospective study. Medical Journal of Dr. D.Y. Patil University. 2014 Mar-Apr; 7(2): 177-181.
13. Zwirewich CV, Vedal S, Miller RR, Muller NL. Solitary pulmonary nodule: high-resolution CT and radiologic-pathologic correlation. Radiology.1991 May; 179 (2): 469-476.

14. Ningappa R, Ashwini, John DS, Santosh. Role of MDCT in the evaluation of bronchogenic carcinoma. SSRG International Journal of Medical Science. 2015 Mar; 2(3): 21-23.

15. Woodring JH, Fried AM. Significance of wall thickness in solitary cavities of the lung: a follow-up study. AJR Am J Roentgenol.1983 Mar; 140(3):473-74.

16. Siegelman SS, Khouri NF, Leo FP, Fishman EK, Braverman RM, Zerhouni EA. Solitary pulmonary Nodules: CT assessment. Radiology.1986 Aug; 160(2): 307-12.

17. Shetty CM, Lashkar BN, Gandadhar VSS, Ramchandran NR. Changing Pattern of bronchogenic carcinoma: A statistical variation or a reality? Ind J Radiol Imag. 2005; 15(1):233-238.

18. Madan M, Bannur H. Evaluation of fine needle aspiration cytology in the diagnosis of lung lesions. Turk J Path. 2010; 26: 1-6.

19. JayaShankar E, Pavani B, Chandra E, Reddy R, Srinivas M, Shah A. Computed tomography guided percutaneous thoracic: Fine needle aspiration cytology in lung and mediastinum. J Cytol Histol. 2010; 107:1-3.

20. Singh JP, Setia V. Computed tomography (CT) guided transthoracic needle aspiration cytology in difficult thoracic mass lesions-not approachable by USG. Indian J Radiol Imaging. 2004; 14 (4): 395-400.

21. Datta A. Radio-image guided FNAC: A hospital based study. Indian Medical Journal. 2009 Oct; 103 (10): 331-34.

22. Konjengbam $\mathrm{R}$, Singh $\mathrm{N} \mathrm{B}$, Gatphoh $\mathrm{S}$ G. Computed tomography guided percutaneous transthoracic fine needle aspiration cytology of pulmonary mass lesions: Two years cross sectional study of 61 cases. Journal of Medical Society. 2014 May- Aug; 28(2): 112-116.

23. Baby J, George P. Computed tomography guided fine needle aspiration cytology of thoracic lesions: A retrospective analysis of 114 cases. IOSR Journal of 
Dental and Medical Sciences. 2014 Jan; 13(1): 47-52.

24. Piplani S, Mannan R, Lalit M, Manjari M, Bhasin

TS, Bawa J. Cytologic-Radiologic Correlation Using
Transthoracic CT-Guided FNA for Lung and Mediastinal Masses: Our Experience. Analytical cellular pathology (Amsterdam). 2014;2014:343461. doi:10.1155/2014/343461. (accessed on June 14, 2016).

\section{How to cite this article?}

Biswas P, Datta A, De A, Sinha LK. Pulmonary Mass Lesions: CT Scan Diagnostic-Impressions and FNAC Diagnoses A Correlative Study. Int J Med Res Rev 2016;4 (6):1052-1062.doi: 10.17511/ijmrr.2016.i06.33. 